\title{
ANALISA PERENCANAAN DAN PENGENDALIAN PERSEDIAAN PRODUKSI FOAM DENGAN METODE EXPONENTIAL SMOOTHING.(Studi kasus pada PT. BESTARI MULIA)
}

\author{
Sitta Mega Afrista**) dan Yunia Dwie Nurcahyanie*)
}

\begin{abstract}
Abstrak
Perkembangan industri manufaktur saat ini berkembang begitu pesat, dengan itu persaingan antar perusahaan akan semakin kompetitif, maka persaingan akan semakin meningkat. Perusahaan dituntut untuk lebih meningkatkan mutu produknya dan selain itu tidak kalah penting yaitu pelayanannya (tepat waktu dan tepat jumlahnya). Oleh karena itu salah satu sumber daya memegang peran penting dalam perusahaan adalah pengendalian bahan baku. Berdasarkan data permintaan foam periode Januari 2011 sampai Desember 2013, maka perhitungan peramalan dilakukan dengan menggunakan metode Exponential Smoothing ternyata hasilnya memiliki nilai error terendah adalah $(\alpha=0,1)$, sedangkan untuk item sisanya nilai error terendah adalah $(\alpha=0,9)$. Dan jika dibandingkan dengan metode dekomposisi ternyata dengan menggunakan metode eksponensial lebih baik karena tingkat errornya lebih rendah, tapi jika kita ingin menentukan nilai peramalan dalam 1 kuartal (3 Bulan) metode dekomposisi bisa digunakan dalam peramalan ini.
\end{abstract}

Kata kunci : Peramalan, perencanaan produksi, pengendalian bahan baku

\section{PENDAHULUAN}

Pengukuran permintaan adalah usaha untuk mengetahui permintaan atas suatu produk atau sekelompok produk di masa lalu dan di masa yang sekarang dalam kendala suatu asset kondisi tertentu. Bahan baku merupakan salah satu faktor yang sangat vital bagi berlangsungnya suatu proses produksi. Persediaan bahan baku yang melebihi kebutuhan akan menimbulkan biaya extra atau biaya simpan yang sangat tinggi, sedangkan jumlah persediaan yang terlalu sedikit akan menimbulkan kerugian yaitu terganggunya proses produksi dan juga mengakibatkan hilang kesempatan uantuk memperoleh keuntungan apabila ternyata permintaan pada kondisi yang sebenarnya melebihi permintaan yang diperkirakan.

Agar tetap dapat bertahan dalam situasi persaingan pasar yang begitu ketat, perusahaan perlu melakukan penekanan biaya persediaan serta penghematan biaya untuk pembelian bahan baku. PT. Bestari Mulia adalah salah satu perusahaan yang bergerak di bidang produksi pembuatan produk FOAM \& SPRING MATRESS. Namun perusahaan sering mengalami banyak kendala dalam melaksanakan kegiatan operasionalnya. Dan tidak ada permberitahuan apabila persediaan bahan baku hampir habis. Hal ini terjadi karena tidak adanya sistem yang mendukung untuk mengelolah data inventory, sehingga sistem produksi tidak bisa memenuhi demand dengan efektif, dikarenakan tidak terhubungnya antara devisi gudang (Warehouse) dengan devisi produksi. Melihat dari masalah yang ada pada PT. Bestari Mulia, maka perlunya pembangunan sistem informasi (PPIC) karena bisa mengontrol kelancaran sistem produksi.

Mengingat bahwa masalah persediaan mencakup bidang yang luas dan guna membatasi masalah yang akan diuraikan maka penulis tertarik untuk membahas tentang perencanaan dan pengendalian persediaan produksi.

\section{Batasan dan Ruang Lingkup}

Berdasarkan masalah diatas maka penulis hanya membatasi masalah dan ruang lingkup tentang yang terjadi di dalam yaitu :

1. Mengenai bagaimana perusahaan mengendalikan perencanaan persediaan produksi foam.

2. Peramalan permintaan pada periode selanjutnya agar bisa terpenuhi semua permintaan produksi foam dengan menggunakan metode Exponential Smoothing

3. Data yang digunakan yaitu bulan Januari 2011 sampai dengan Desember 2013.

4. Dikarenakan banyaknya item maka peneliti hanya membatasi beberapa produk yaitu big ten untuk perencanaan produksi foam.

\footnotetext{
**) Mahasiswa Teknik Industri

*) Dosen Teknik Industri Universitas PGRI Adi Buana Surabaya
} 


\section{Perumusan Masalah}

Seperti yang dijelaskan diatas bahwa dalam membuat suatu forecast untuk stock barang ada beberapa metode salah satunya dengan menggunakan metode time series. Maka dengan ini dapat diambil dengan kesimpulan sebagai berikut :

"Bagaimana menerapkan metode exponential smoothing dalam meramalkan kebutuhan Foam perusahaan PT Bestari Mulia".

\section{Tujuan dan Manfaat}

1. Tujuan

Berdasarkan rumusan masalah diatas, tujuan dari proposal ini asalah penerapan Metode Exponential Smoothing utnuk peramalan perencanaan persediaan produksi foam pada PT. Bestari Mulai.

2. Manfaat

Adapun manfaat yang dapat diambil dari penelitian ini adalah ;

Sebagai bahan masukan serta pertimbangan bagi perusahaan dalam pengambilan keputusan yang berhubungan dengan kebijakan perusahaan.

\section{METODE PENELITIAN \\ Tahapan Penelitian}

Penelitian ini dimulai dengan pencarian ide dan gagasan melalui studi pendahuluan, baik melalui studi pustaka media cetak maupun elektronik (internet), dan studi dari penelitian terdahulu. Lalu setelah ditentukan tema, langkah selanjutnya adalah menentukan batasan masalah yang akan diteliti lebih lanjut dan penentuan variable - variable apa saja yang mempengaruahi objek penelitian.

Langkah selanjutnya adalah menentukan data apa saja yang dibutuhkan dan dilanjutkan dengan pengumpulan data baik data primer maupun data sekunder melalui wawancara, observasi langsung, studi literatur dan pengumpulan data historis perusahaan.

Pengolahan data yang dimulai dengan melakukan pengelompokan produk, dilanjutkan dengan peramalan tingkat permintaan untuk periode selanjutnya dengan menggunakan data penjualan pada periode-periode sebelumnya. Selanjutnya adalah menentukan tingakat persediaan yang optimal dengan menggunakan metode Exponential Smoothing. Setelah itu dilakukan perbandingan efisiensi biaya dari metode yang digunakan perusahaan dan metode yang digunakan peneliti. Hasil pengolahan dengan metode ini diharap dapat memberikan rekomendasi tingkat persediaan produksi foam yang juga tetap menjada ketersediaannya bagi perusahaan.

\section{A. Variabel Penelitian dan Definisi Operasional}

1. Variabel

Variabel adalah karakteristik dari suatu konsep yang mengandung dua atau lebih yang berbeda. Menurut Moh. Nasir (1999 : 6) mengemukakan bahwa :"variabel adalah konsep yang mempunyai bermacam-macam nilai".

Adapun variabel penelitian ini adalah

a) Variabel bebas: Metode Exponential Smoothing.

b) Variabel terikat: Kelancaran proses produksi foam.

2. Definisi Operasional Variabel Adapun definisi operasional variabelnya adalah :

a. Persediaan bahan baku foam Yang dimaksud persediaan bahan baku foam dalam penelitian adalah suatu analisa yang dilakukan dengan terlebih dahulu merencanakan kebutuhan bahan baku foam. Kemudian dilakukan pengendalian guna lebih mengefektifkan atau memaksimalkan bahan baku yang akan digunakan untuk proses produksi dengan metode Exponential.

b. Kelancaran proses produksi foam Yang dimaksud kelancaran produksi foam dalam penelitian ini adalah kontinuitas suatu kegiatan produksi yang dilakukan guna memproses bahan baku menjadi barang jadi atau setengah jadi.

\section{B. Metode Pengumpulan Data}

Data yang digunakan dalam penelitian ini adalah data primer dan data sekunder, baik yang bersifat kuantitatif maupun kualitatif. Informasi tersebut diperoleh melalui wawancara terstruktur kepada manajemen PT. BESTARI MULIA dan hasil pengamatan 


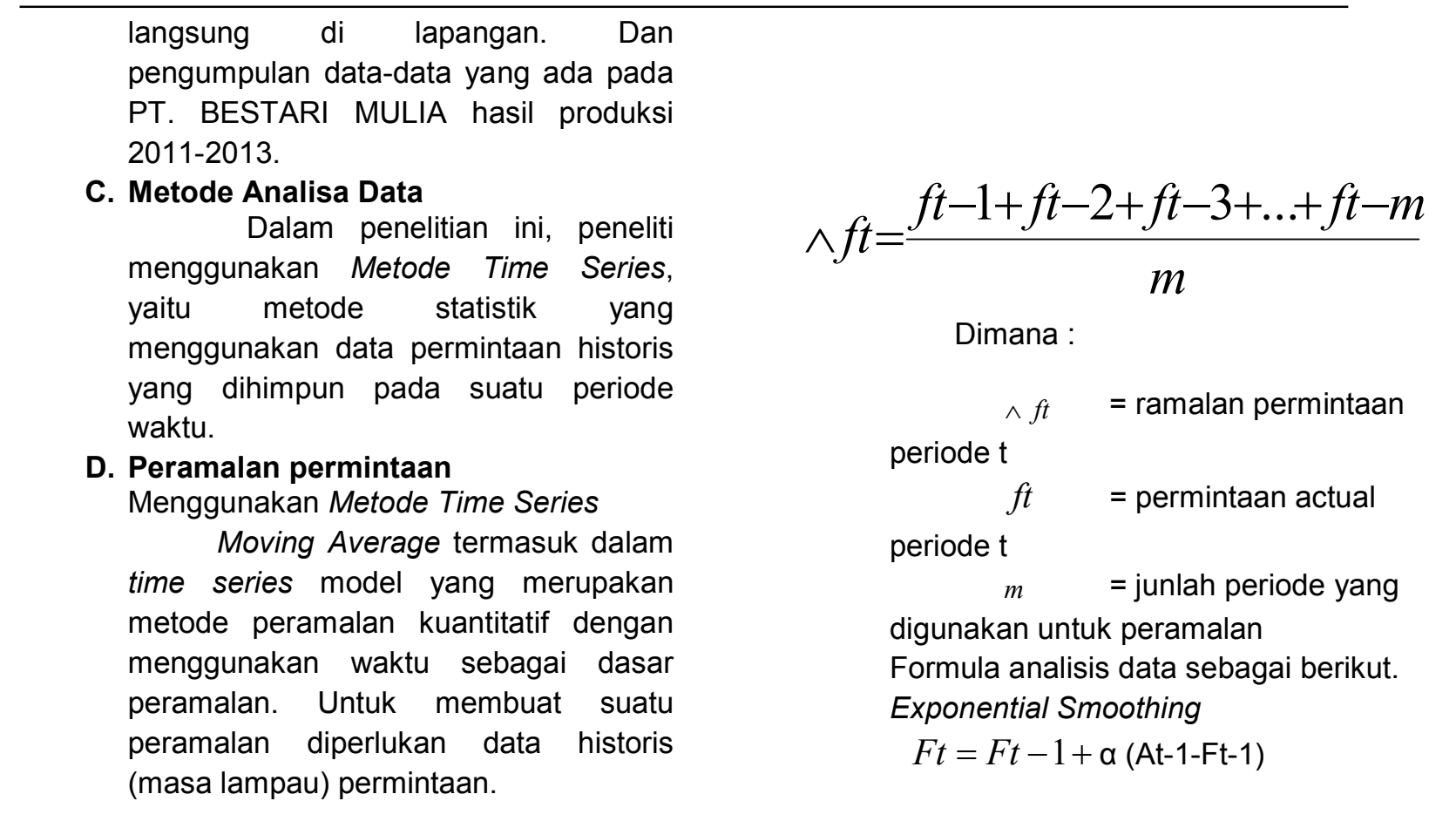

\section{PENYAJIAN DATA DAN ANALISIS DATA}

1. Penyajian Data

Produk foam yang di diproduksi oleh PT Bestari Mulia ada 28 jenis dan untuk data penelitian ini hanya mengambil sampel 10 besar yang sering diproduksi dan permintaan terbanyak dari konsumen. 10 besar sampel tersebut disajikan dalam tabel 1 seperti dibawah ini.

Tabel 1 Kebutuhan Demand Foam Tahun 2011-2013

\begin{tabular}{|c|c|c|c|c|c|c|c|c|c|c|c|c|c|c|c|}
\hline \multirow{3}{*}{ Bulan } & \multicolumn{3}{|c|}{1} & \multicolumn{3}{|c|}{2} & \multicolumn{3}{|c|}{3} & \multicolumn{3}{|c|}{4} & \multicolumn{3}{|c|}{5} \\
\hline & \multicolumn{3}{|c|}{ Hasil produksi $\left(\mathrm{m}^{3}\right)$} & \multicolumn{3}{|c|}{ Hasil produksi ( $\left.\mathbf{m}^{3}\right)$} & \multicolumn{3}{|c|}{ Hasil produksi $\left(\mathbf{m}^{3}\right)$} & \multicolumn{3}{|c|}{ Hasil produksi $\left(\mathrm{m}^{3}\right)$} & \multicolumn{3}{|c|}{ Hasil produksi $\left(\mathrm{m}^{3}\right)$} \\
\hline & 2011 & 2012 & 2013 & 2011 & 2012 & 2013 & 2011 & 2012 & 2013 & 2011 & 2012 & 2013 & 2011 & 2012 & 2013 \\
\hline 1 & 0 & 6000 & 0 & 0 & 12000 & 12000 & 0 & 18000 & 18000 & 9000 & 12000 & 0 & 0 & 30000 & 24000 \\
\hline 2 & 0 & 6000 & 12000 & 0 & 6000 & 24000 & 0 & 45000 & 24000 & 12000 & 9000 & 24000 & 0 & 18000 & 36000 \\
\hline 3 & 6000 & 12000 & 12000 & 0 & 12000 & 12000 & 0 & 0 & 18000 & 18000 & 18000 & 24000 & 3000 & 9000 & 24000 \\
\hline 4 & 0 & 0 & 15000 & 0 & 6000 & 12000 & 0 & 30000 & 21000 & 0 & 0 & 12000 & 0 & 18000 & 36000 \\
\hline 5 & 0 & 12000 & 0 & 0 & 9000 & 6000 & 0 & 0 & 12000 & 0 & 21000 & 24000 & 0 & 24000 & 42000 \\
\hline 6 & 6000 & 0 & 6000 & 0 & 0 & 12000 & 0 & 24000 & 18000 & 27000 & 12000 & 12000 & 18000 & 15000 & 30000 \\
\hline 7 & 0 & 3000 & 6000 & 0 & 9000 & 18000 & 0 & 24000 & 30000 & 21000 & 6000 & 24000 & 0 & 24000 & 54000 \\
\hline 8 & 0 & 6000 & 6000 & 0 & 6000 & 12000 & 0 & 21000 & 22500 & 0 & 0 & 24000 & 0 & 12000 & 36000 \\
\hline 9 & 0 & 9000 & 12000 & 0 & 18000 & 18000 & 0 & 24000 & 36000 & 12000 & 18000 & 24000 & 0 & 12000 & 87000 \\
\hline 10 & 3000 & 18000 & 0 & 0 & 0 & 12000 & 0 & 18000 & 30000 & 3000 & 6000 & 12000 & 0 & 12000 & 6000 \\
\hline 11 & 0 & 0 & 12000 & 6000 & 6000 & 12000 & 15000 & 27000 & 0 & 12000 & 6000 & 12000 & 12000 & 21000 & 24000 \\
\hline 12 & 18000 & 12000 & 6000 & 12000 & 0 & 12000 & 21000 & 18000 & 18000 & 12000 & 0 & 12000 & 3000 & 36000 & 36000 \\
\hline
\end{tabular}


Sitta Mega Afrista \& Yunia Dwie Nurcahyanie : Analisa Perencanaan dan Pengendalian Persediaan Produksi Foam dengan Metode Exponential Smoothing

\begin{tabular}{|c|c|c|c|c|c|c|c|c|c|c|c|c|c|c|c|}
\hline \multirow{3}{*}{ Bulan } & \multicolumn{3}{|c|}{6} & \multicolumn{3}{|c|}{7} & \multicolumn{3}{|c|}{8} & \multicolumn{3}{|c|}{9} & \multicolumn{3}{|c|}{10} \\
\hline & \multicolumn{3}{|c|}{ Hasil produksi $\left(\mathrm{m}^{3}\right)$} & \multicolumn{3}{|c|}{ Hasil produksi $\left(\mathrm{m}^{3}\right)$} & \multicolumn{3}{|c|}{ Hasil produksi $\left(\mathrm{m}^{3}\right)$} & \multicolumn{3}{|c|}{ Hasil produksi $\left(\mathrm{m}^{3}\right)$} & \multicolumn{3}{|c|}{ Hasil produksi $\left(\mathrm{m}^{3}\right)$} \\
\hline & 2011 & 2012 & 2013 & 2011 & 2012 & 2013 & 2011 & 2012 & 2013 & 2011 & 2012 & 2013 & 2011 & 2012 & 2013 \\
\hline 1 & 0 & 54000 & 42000 & 9000 & 24000 & 18000 & 0 & 42000 & 54000 & 0 & 24000 & 18000 & 0 & 6000 & 6000 \\
\hline 2 & 0 & 21000 & 90000 & 0 & 30000 & 12000 & 0 & 36000 & 48000 & 0 & 6000 & 30000 & 0 & 6000 & 6000 \\
\hline 3 & 6000 & 18000 & 12000 & 6000 & 9000 & 12000 & 0 & 54000 & 48000 & 3000 & 15000 & 6000 & 3000 & 9000 & 12000 \\
\hline 4 & 0 & 9000 & 42000 & 0 & 33000 & 12000 & 0 & 42000 & 42000 & 0 & 9000 & 21000 & 0 & 9000 & 12000 \\
\hline 5 & 0 & 18000 & 48000 & 0 & 27000 & 12000 & 0 & 45000 & 24000 & 0 & 18000 & 6000 & 0 & 0 & 12000 \\
\hline 6 & 6000 & 0 & 30000 & 21000 & 21000 & 12000 & 3000 & 33000 & 42000 & 6000 & 6000 & 6000 & 0 & 9000 & 12000 \\
\hline 7 & 0 & 12000 & 60000 & 0 & 6000 & 24000 & 15000 & 42000 & 63000 & 0 & 6000 & 21000 & 0 & 6000 & 24000 \\
\hline 8 & 12000 & 15000 & 42000 & 21000 & 12000 & 18000 & 12000 & 18000 & 18000 & 6000 & 0 & 24000 & 0 & 0 & 6000 \\
\hline 9 & 6000 & 6000 & 63000 & 18000 & 15000 & 18000 & 18000 & 24000 & 81000 & 9000 & 6000 & 21000 & 9000 & 6000 & 27000 \\
\hline 10 & 0 & 12000 & 45000 & 9000 & 12000 & 24000 & 24000 & 24000 & 60000 & 0 & 6000 & 15000 & 0 & 0 & 6000 \\
\hline 11 & 0 & 12000 & 33000 & 0 & 15000 & 12000 & 21000 & 39000 & 24000 & 0 & 12000 & 18000 & 0 & 12000 & 15000 \\
\hline 12 & 0 & 12000 & 60000 & 9000 & 12000 & 24000 & 12000 & 33000 & 33000 & 15000 & 12000 & 24000 & 6000 & 6000 & 15000 \\
\hline
\end{tabular}

\section{PEMBAHASAN}

Dari hasil penelitian diatas maka dapat disimpulkan bahwa dalam setiap item peramalan memiliki tingkat error yang berbeda dari setiap $(\alpha)$, seperti yang terdapat pada kualitas SR WHITE dan D 19 VL WHITE yang memiliki nilai error terendah adalah $(\alpha=0,1)$, sedangkan untuk item sisanya nilai error terendah adalah $(\alpha=0,9)$. Dan jika dibandingkan dengan metode dekomposisi ternyata dengan menggunakan metode eksponensial lebih baik karena tingkat errornya lebih rendah, tapi jika kita ingin menentukan nilai peramalan dalam 1 kuartal (3 Bulan) metode dekomposisi bisa digunakan dalam peramalan ini.

Sehingga dari kesimpulan diatas bahwa dalam sebuah peramalan dengan menggunakan Metode Eksponensial Smoothing memiliki nilai peramalan yang berbeda satu sama lainnya tergantung kita akan memilih nilai ( $\alpha$ ) yang paling sesuai. Hasil peramalan kebutuhan foam dengan metode Exponential Smoothing dapat dilihat pada tabel 2 .

Tabel 2 : Tabel hasil peramalan kebutuhan foam dengan metode Exponential Smoothing

\begin{tabular}{|c|c|c|c|}
\hline Big ten & Forecas 2014 & Demand 2014 & GAP \\
\hline SR WHITE & 27909 & 12000 & $2,32 \%$ \\
D 13 HARD WHITE (206) & 47773 & 60000 & $0,8 \%$ \\
D 15 WHITE & 85659 & 66000 & $1,3 \%$ \\
D 19 VL WHITE & 47682 & 39000 & $1,22 \%$ \\
D 22 TM YELLOW & 132409 & 144000 & $0,92 \%$ \\
D 24 LIGH GREEN & 159864 & 288000 & $0,55 \%$ \\
BC 14 YELLOW & 61000 & 90000 & $0,68 \%$ \\
BC 16 WHITE & 168591 & 108000 & $1,56 \%$ \\
BC 21 YELLOW & 62319 & 30000 & $2 \%$ \\
BC 25 YELLOW & 45909 & 54000 & $0,85 \%$ \\
\hline
\end{tabular}


Gambar 1 Merupakan grafik hasil peramalan kebutuhan foam yang ditunjukkan dengan grafik berwarna merah. Dari gambar tersebut dapat diketahui bahwa hasil peramalan menggunakan metode exponential smoothing dengan $\alpha=$ 0,5 menghasilkan grafik yang selalu berada dibawah grafik kebutuhan foam yang sebenarnya. Hal ini menunjukkan adanya tingkat kesalahan nilai peramalan,

sehingga menghasilkan nilai yang berbeda jauh dengan kebutuhan foam yang sebenarnya karena banyak faktor yang tidak diikutsertakan dalam perhitungan seperti kenaikan harga foam, biaya-biaya dII.

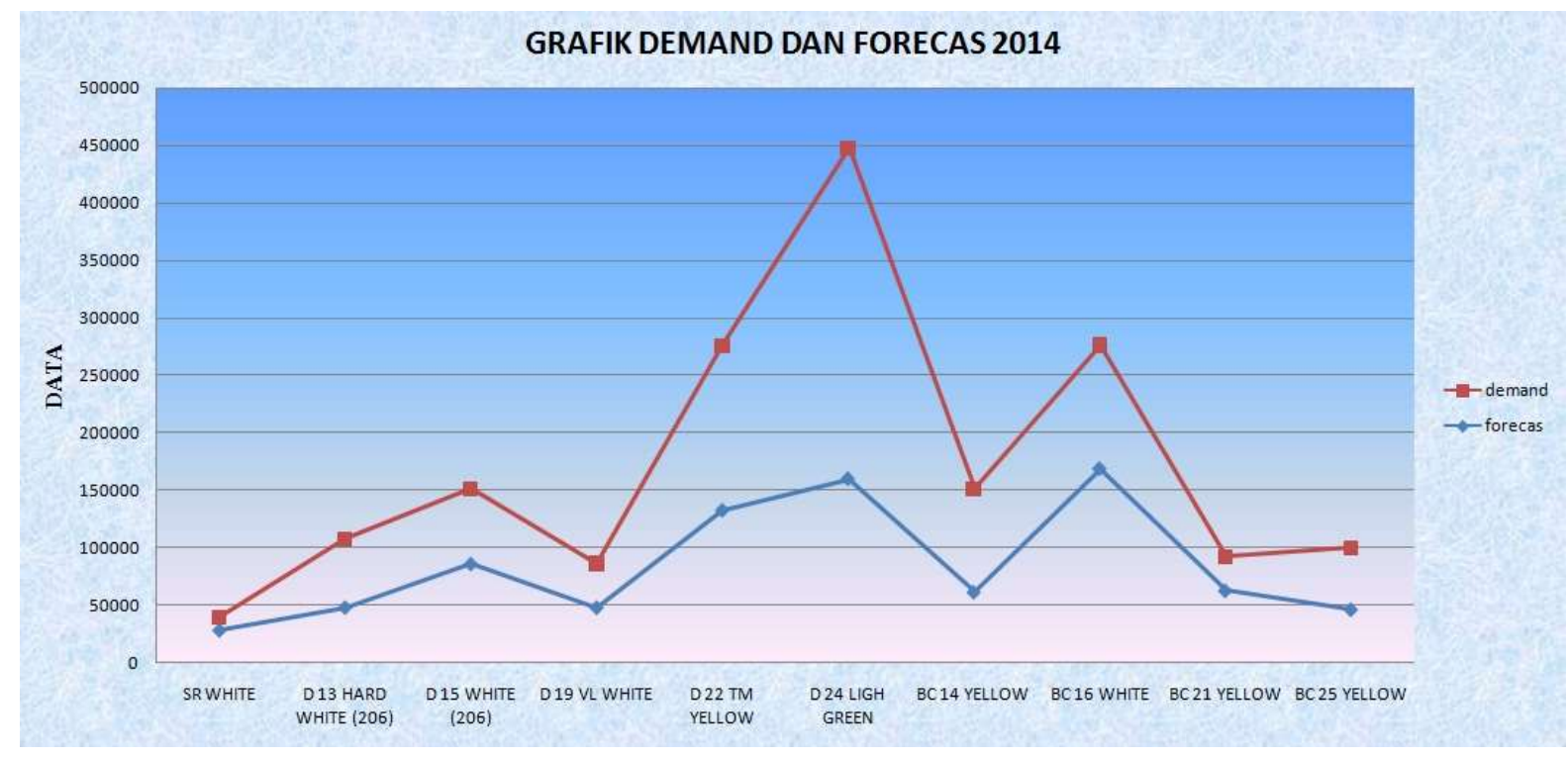

Gambar 1 : Grafik Demand dan Forecas 2014

\section{SIMPULAN DAN SARAN}

Nilai peramalan kebutuhan foam dengan metode exponential smoothing pada penelitian ini menghasilkan nilai yang berbeda dengan nilai kebutuhan foam yang sebenarnya, ditunjukkan dengan jumlah kuadrat kesalahan yang semakin besar. Metode exponential smoothing kurang tepat untuk diterapkan pada penelitian ini karena hasil peramalan masih memuat kesalahan atau masih sangat jauh dari kebutuhan sebenarnya.

Peramalan pada produk big ten memiliki nilai MAD (nilai tengah kesalahan), MSE (nilai tengah kesalahan kuadrat), dan MAPE (nilai tengah kesalahan persentase absolute) terendah pada ( $\alpha$ $=0,9)$. Dengan metode dekomposisi lebih efisien untuk meramalkan kebutuhan dimasa depan ,sehingga stock untuk kebutuhan 3 bulan kedepan lebih terencana .Dan biaya yang dikeluarkan oleh perusahaan pun akan lebih berkurang karena akan mengurangi stock barang yang slow moving. Dalam penelitian ini hasil peramalan belum tentu tepat karena banyak faktor yang tidak diikutsertakan dalam perhitungan. Maka dari itu untuk penelitian selanjutnya, disarankan untuk menggunakan metode yang lain seperti rata-rata bergerak (moving average), ARIMA, dll. ARIMA sering juga disebut metode runtun waktu. ARIMA sangat baik ketepatannya untuk peramalan jangka pendek, sedangkan untuk peramalan jangka panjang ketepatan peramalannya kurang baik. Biasanya akan cenderung flat (mendatar/konstan) untuk periode yang cukup panjang 


\section{DAFTAR PUSTAKA}

Rangkuti, F. 2004. Manajemen Persediaan Aplikasi di Bidang Bisnis. PT Raja Grafindo Persada, Jakarta.

Baroto. 2002.Perencanaan dan pengendaliaan Produksi. Jakarta : Ghalia, Indonesia.

Arman Hakim, Nasution.2008.Perencanaan dan pengendalian produksi.guna widya, Surabaya.

Sri Kumalaningsi.2013. Pengertian dan fungsi proses produksi. UI Press, Jakarta. Montgomery, D.C, L.A Johnson and J.S Gardiner. 1990. Forecasting and Time Series Analysis. Mc Graw Hill Inc, Singapura.

Subandowo, M dan Rufi'i. 2006, Pedoman Penelitian, Surabaya, Universitas PGRI Adi Buana

Http: //Pusdatin/time_series.com tanggal akses: 3 November 2013

http://www.muggom.com/pabrik foam/index.htm tanggal akses: 1 Februari 2014 